University of Nebraska - Lincoln

DigitalCommons@University of Nebraska - Lincoln

Roman L. Hruska U.S. Meat Animal Research

U.S. Department of Agriculture: Agricultural Center

Research Service, Lincoln, Nebraska

1996

\title{
A Search for Quantitative Trait Loci for Ovulation Rate in Cattle
}

\author{
A. N. Blattman \\ University of Wisconsin - Madison \\ B. W. Kirkpatrick \\ University of Wisconsin - Madison \\ K. E. Gregory \\ USDA-ARS
}

Follow this and additional works at: https://digitalcommons.unl.edu/hruskareports

Blattman, A. N.; Kirkpatrick, B. W.; and Gregory, K. E., "A Search for Quantitative Trait Loci for Ovulation Rate in Cattle" (1996). Roman L. Hruska U.S. Meat Animal Research Center. 221.

https://digitalcommons.unl.edu/hruskareports/221

This Article is brought to you for free and open access by the U.S. Department of Agriculture: Agricultural Research Service, Lincoln, Nebraska at DigitalCommons@University of Nebraska - Lincoln. It has been accepted for inclusion in Roman L. Hruska U.S. Meat Animal Research Center by an authorized administrator of DigitalCommons@University of Nebraska - Lincoln. 
Animal Genetics, 1996, 27, 157-162

\title{
A search for quantitative trait loci for ovulation rate in cattle
}

\author{
A N Blattman, B W Kirkpatrick, K E Gregory
}

\begin{abstract}
Summary
Seventy-seven polymorphic microsatellites were analysed in offspring of three elite sires that were part of the foundation of an experimental population selected for twinning rate at the US Meat Animal Research Center, Clay Center, Nebraska. All females were assessed for ovulation rate by rectal palpation of corpora lutea over 8-10 consecutive oestrous cycles from approximately 12 to 18 months of age, and associations between ovulation rate and sire allele were examined in each of the three sire groups. A preliminary analysis was performed using selectively genotyped daughters of each sire. Markers found significant or approaching significance were also genotyped in all daughters, sons and granddaughters of these sires. A test of marker associations limited to the granddaughter data provided an independent confirmation of marker effect and significance relative to the initial test with daughter data. Putative ovulation rate quantitative trait loci were detected on chromosomes 7 and 23. Marker UWCA20 on chromosome 7 was associated with an effect in excess of one phenotypic standard deviation and accounted for approximately $10 \%$ of phenotypic variation ovulation rate. Marker CYP21 (steroid 21-hydroxylase) on chromosome 23 was associated with an effect of slightly less than half a phenotypic standard deviation and accounted for approximately $4 \%$ of phenotypic variation.
\end{abstract}

Keywords: microsatellites, ovulation rate, quantitative trait loci, twinning

\section{Introduction}

Reproductive rate has a large impact on production costs of different animal species. For example, an average beef cow produces only 0.7 calves per annum (Bellows et al. 1979), a value that compares poorly to 130-150 offspring per annum in meat chickens (Andrews et al. 1988). Similarly, when considering cost

\section{Correspondence: B W Kirkpatrick.}

Accepted 7 February 1996 efficiency, 33\% of cost input for producing a kilogram of protein is attributed to maintenance of the bovine breeding female, compared with approximately $11 \%$ in chickens (Dickerson 1978). Through results from experimentation and computer simulation of beef production systems, Dickerson et al. (1988) suggested that input costs per unit of beef output could be reduced by $20-30 \%$ for that proportion of the herd producing twins compared to single calves. As a consequence, profitability of beef production should improve with increased reproductive rate, provided additional management is available to overcome negative effects associated with twin births (Anderson et al. 1979).

The majority of economically important traits, such as reproductive rate in cattle, are thought to be controlled by the combined action of many genes, modified by various environmental factors. These genes are termed quantitative trait loci (QTL). However, for many economic traits there may be only a few genes that account for a large proportion of the genetic variation observed. Therefore, if it were possible to identify QTL responsible for a significant proportion of the genetic variation in reproductive rate in cattle, or at least detect a closely linked genetic marker that is coinherited with the QTL, then selection response could be enhanced by selecting desirable alleles at those loci.

The experimental population that provided data for this study was established in 1981 at the US Meat Animal Research Center (MARC) at Clay Centre, Nebraska (Gregory et al. 1990). Current twinning rate in the experimental population is approximately $30 \%$. Twinning rate is approximately $1 \%$ for beef breeds and $4 \%$ for dairy breeds in which selection has not been practised (Rutledge 1975).

This paper reports results of experiments carried out to determine whether any genes closely linked to a series of molecular markers have a role in increased ovulation rate and twinning frequency within the MARC experimental population. Initially, a candidate gene study was undertaken; this study has now progressed to a more comprehensive genome search involving 77 relatively evenly spaced molecular markers, primarily microsatellites. 
158

Blattman,

Kirkpatrick, Gregory

\section{Materials and methods}

\section{Animal resources}

In this experimental population of approximately 750 calving females, selection has focused on increasing twinning rate by using ovulation rate in puberal heifers as a primary selection criterion. Progeny-proven sires were mated to approximately $25 \%$ of the females with highest estimated breeding values (EBV) for twinning, and approximately 30 young sires resulting from these matings were mated to the remaining $75 \%$ of the females to produce $6-10$ daughter progeny on which ovulation rate was determined over 8-10 consecutive oestrous cycles (Gregory et al. 1990).

In terms of marker association work described in this paper, a single-trait animal model was used to estimate breeding value for ovulation rate. Starting at $\mathbf{1 2 - 1 3}$ months of age, ovulation rate was determined by rectal palpation of corpora lutea for 8-10 consecutive oestrous cycles (Gregory et al. 1990). The mean raw ovulation rate (averaged over 8-10 cycles) for the MARC experimental population was 1.145 ova per oestrous cycle with a standard deviation of $0 \cdot 174$. EBVs were calculated for average ovulation rate using best linear unbiased prediction (BLUP) statistical methodology within a complete animal model, fitting significant effects of heifer birth-year-season, age of heifer when ovulation rate was observed, and month of observation. The heritability of ovulation rate, averaged over eight consecutive oestrous cycles, was 0.38 (Echternkamp et al. 1990a). The computer program used to estimate breeding value for ovulation rate was the Prediction and Estimation package, PEST (Groeneveld et al. 1990).

Animals from three elite sire families (784403, $839802 \& 839803$, the latter being paternal halfsibs) were selectively genotyped (Darvasi \& Soller 1992). These sires were chosen based on their relatively large numbers of daughters and their high EBV for ovulation rate. DNA was extracted from daughters whose EBV fell within the upper and lower $25 \%$ range of each sire family. To obtain an unbiased estimate of gene effect, those markers which appeared significant in daughter and granddaughter generations were subsequently genotyped in all daughters from the relevant sire family.

There were also a number of sons of each sire available, which in turn produced a significant number of granddaughters. In total, sire group 784403 consisted of 82 daughters, 15 sons and 116 paternal granddaughters; sire group 839802 consisted of 40 daughters, 12 sons and 158 paternal granddaughters and sire group 839803 consisted of 81 daughters, 24 sons and 236 paternal granddaughters.

\section{DNA typing}

DNA was extracted from white blood cells, semen or skin biopsies. Skin biopsy was preferred as a DNA source to eliminate chimerism associated with leucocyte populations from twins. DNA was extracted using the method reported by Mullenbach et al. (1989).

Polymerase chain reaction (PCR) was carried out in an MJ Research thermal controller (MJ Research Inc., MA, USA). Aliquots of approximately $50 \mathrm{ng}$ of DNA were amplified $\left(\mathrm{V}_{\mathrm{t}}=10 \mu \mathrm{l}\right)$ using 20 pmoles $\mathrm{ml}^{-1}$ primers, $120 \mu \mathrm{M}$ dNTPs and $1.5 \mathrm{mM}-3 \mathrm{mM} \mathrm{MgCl}_{2}$. Reactions were preheated to $95^{\circ} \mathrm{C}$ for $1.5 \mathrm{~min}$, then cycled 4 times at $94^{\circ} \mathrm{C}$ for $1 \mathrm{~min}, 48^{\circ} \mathrm{C}-63^{\circ} \mathrm{C}$ (depending on microsatellite) for $1 \mathrm{~min}$ and $72^{\circ} \mathrm{C}$ for $1 \mathrm{~min}$. The next 22-24 cycles consisted of $90^{\circ} \mathrm{C}$ for $25 \mathrm{~s}$, $47-62^{\circ} \mathrm{C}$ for $40 \mathrm{~s}$ and $72^{\circ} \mathrm{C}$ for $45 \mathrm{~s}$, and finally the reaction was maintained at $72^{\circ} \mathrm{C}$ for $5 \mathrm{~min}$.

After amplification, samples were mixed with $3 \mu \mathrm{l}$ of loading dye and loaded on $7 \%$ non-denaturing polyacrylamide gels and electrophoresed for 1400-3200 volt-hours. Gels were stained with ethidium bromide before being photographed under UV light.

Unless otherwise stated, all markers mentioned in this study have been previously described in mapping papers of Barendse et al. (1994), Bishop et al. (1994) and Sun et al. (1994).

Of the candidate genes examined, both IGF-1 and the putative bovine $\mathrm{Fec}^{\mathrm{B}}$ (Montgomery 1993) analogue were identified by microsatellites. An AC dinucleotide repeat was resident within the 5 ' flanking region of IGF-1, whilst $\mathrm{Fec}^{\mathrm{B}}$ was known to be closely linked in sheep (G. W. Montgomery, pers. commun.) to bovine microsatellite BM1329. Growth hormone and INHA were both identified as single-stranded conformational polymorphisms.

The recent development of the bovine genetic map (Barendse et al. 1994; Bishop et al. 1994) has resulted in a plethora of markers. As a consequence, the study was extended beyond a candidate gene analysis and markers were chosen in an effort to provide a broad genomic coverage across the three sires of at least two markers per chromosome. Once a marker was determined to be associated with ovulation rate, markers flanking that locus were also genotyped.

\section{Statistical analysis}

In general, statistical analysis performed in this study was two-stage in nature. Firstly, all infor- 
mative markers were selectively genotyped in daughters of the three elite sires. Secondly, in an effort to validate any potential associations, those markers that appeared significant, or approached significance at the $5 \%$ level, plus all informative candidate genes, were genotyped in sons and, where informative, in granddaughters. Information from the granddaughter generation was also considered separately as an independent data set. In this case it was appropriate to evaluate significance relative to a one-sided hypothesis based on the results of the initial study.

The parameter that best describes the association between marker genotype and ovulation rate was chromosome substitution effect, difference between ovulation rate of offspring inheriting marker allele $A_{1}$ versus those receiving marker allele $A_{2}$ from a heterozygous sire $\left(A_{1} A_{2}\right)$. However, for offspring heterozygous for sire alleles $\left(A_{1} A_{2}\right)$ it was impossible to determine whether they inherited marker allele $A_{1}$ or $A_{2}$. In order to utilize such offspring, genotypic probability was calculated in a manner similar to that described by Dentine \& Cowan (1990). For ambiguous offspring, the expected segregation of the sire allele was dependent upon frequency of that allele in the dam population. Allele frequencies were estimated using genotypes of daughters, sons and a sample of 25 individuals from the experimental population (dam contemporaries).

The model used to test for effects of sire alleles was:

$\mathrm{Y}_{i j}=\alpha+\mathrm{b}_{j}(\mathrm{x})+\mathrm{e}_{i j}$

where $\mathrm{Y}_{i j}=\mathrm{EBV}$ of $j^{\text {th }}$ individual for average ovulation rate; $\alpha=$ regression intercept; $b_{j}=$ chromosome substitution effect sire allele $A_{1}$ vs sire allele $A_{2} ; x=$ probabiity of inheriting sire allele $\mathrm{A}_{1} ; \mathbf{e}_{i j}=$ residual deviation not accounted for in model.

Since sire allele inheritance is treated as a probability and incorporated in the model as a covariate, this method permits the inclusion of data from all animals. Given the limited number of observations available for this study, this approach is preferred to the alternative of dropping ambiguous genotypes from the analysis.

\section{Results}

In all, 77 markers were genotyped in this study, of which 43 were informative in sire $784403 ; 45$ were informative in sire 839802; and 44 were informative in sire 839803 . In addition, eight markers were homozygous in all three sires. Hence, approximately $57 \%$ of markers were informative (sire heterozygous) in any one sire family. An overall genomic distribution of approximately two markers per chromosome across the three sires was achieved for all chromosomes, except chromosomes 24, 26 and 29, which had one marker genotyped on each.

Of the four candidate genes examined, three proved informative in at least one sire. Unfortunately, INHA could not be examined because it was homozygous in all three sires. Both BM1329 and IGF-1 approached signifi-

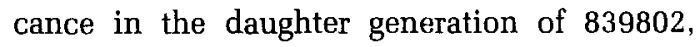
whereas growth hormone, informative only in 784403, was not significant $(P=0.53)$.

The ten markers significant in the daughter generation along with two of the three candidate genes, IGF-1 and BM1329, were subsequently genotyped in sons and informative granddaughters (daughters of heterozygous sons). Genotype data for daughters, sons and granddaughters were combined in an analysis, which contrasts the effects of alternative grandsire alleles (Table 1). Only UWCA4 (-0.042 \pm 0.029 ; $P=0.08)$, in 784403 sire group; UWCA20 (0.12 \pm $0.023 ; P=0.001)$ in 839802 sire group; and CYP21 $(-0.025 \pm 0.011 ; P=0.05)$ in 839803 sire group remained significantly associated with ovulation rate, or approached significance at the $5 \%$ level.

Separate analysis of granddaughter data provided confirmatory results in two of three cases. UWCA20 sire allele 1 was significantly different from sire allele 2 when analysed solely within granddaughters $(0.17 \pm 0.031 ; P<0.0001)$ and was also significantly different when analysed within the granddaughter generation against all other dam alleles grouped into a third allele (0.15 \pm 0.028; $P<0.0001)$. Likewise, CYP21 remained significant when contrasting sire alleles 1 and 2 in the granddaughter generation $(-0.03 \pm 0.014 ; P=0.05)$. However, UWCA4 $(-0.005 \pm 0.032 ; P=0.83)$ was not significant when the analysis was restricted to granddaughter information.

Unfortunately, polymorphism of markers IGF1, ILSTS001, HEL10 and growth hormone was so low that many sons were ambiguous in terms of the sire allele inherited. Thus few granddaughters were informative. In the case of growth hormone, several other linked markers were examined, including MAP2C, CSSM65 and GFAP, but in all cases these were uninformative in all three sires.

To further validate the significance of UWCA20 and CYP21, while resolving the uncertainty surrounding UWCA4, markers were genotyped that flanked these loci (Table 1). Informative markers flanking UWCA4 were 
160

Blattman,

Kirkpatrick, Gregory

ILSTS103 (Kemp et al. 1995) and TGLA337; both were non-significant in sire group 784403. Similarly, TGLA122 also mapped to chromosome 21, and although initially significant in daughter analysis $(P=0.03)$ was not significant upon addition of son and granddaughter information $(P=0 \cdot 26)$. The fact that ILSTS103 in particular was very tightly linked to UWCA4 (W. Barendse, pers. commun.), and, yet not significant, plus the non-significance of this marker in the granddaughter generation, casts considerable doubt on whether UWCA4 was indeed associated with ovulation rate. The discrepancy between significance level for closely linked markers is in part interpretable as a sampling affect related to varying assignment of daughters to ambiguous versus unambiguous sire allele classes and inclusion of different granddaughters in the respective marker analyses.

Table 1. Marker-QTL association for putatively significant markers (a) ${ }^{\dagger}$, candidate genes (b) and flanking markers (c)

\begin{tabular}{|c|c|c|c|c|}
\hline Marker & Chromosome & Animals $(n)$ & $\begin{array}{l}\text { Estimate } \\
( \pm S E M)^{\S}\end{array}$ & Probability \\
\hline \multicolumn{5}{|l|}{ Sire 784403} \\
\hline ILSTS10 $^{\mathrm{C}}$ & 21 & 48 & $-0.050 \pm 0.035$ & $0 \cdot 15$ \\
\hline UWCA4 $4^{i *}$ & 21 & 84 & $-0.042 \pm 0.029$ & 0.08 \\
\hline TGLA $337^{\circ}$ & 21 & 53 & $-0.013 \pm 0.02$ & 0.50 \\
\hline TGLA122 & 21 & 73 & $0.024 \pm 0.02$ & 0.26 \\
\hline TGLA431' & 2 & 63 & $0.017 \pm 0.02$ & 0.40 \\
\hline$I G F-1^{b}$ & 5 & 57 & $0.01 \pm 0.03$ & 0.66 \\
\hline \multicolumn{5}{|l|}{ Sire $\mathbf{8 3 9 8 0 2}$} \\
\hline $\operatorname{CsSM} 29^{\circ}$ & 7 & 28 & $0.061 \pm 0.04$ & $0 \cdot 18$ \\
\hline UWCA $20^{\circ}$ & 7 & 78 & $0.120 \pm 0.023$ & $0.0001 * *$ \\
\hline RM006 ${ }^{\circ}$ & 7 & 42 & $0.077 \pm 0.036$ & $0.04^{\star}$ \\
\hline ILSTSO0 $1^{\mathrm{a}}$ & 7 & 33 & $0.07 \pm 0.04$ & 0.10 \\
\hline $\mathrm{BM} 7160^{\circ}$ & 7 & 36 & $0.17 \pm 0.05$ & $0.0005^{* *}$ \\
\hline$\left[\mathrm{GF}-1^{b}\right.$ & 5 & 34 & $0.03 \pm 0.05$ & 0.53 \\
\hline BM1329 & 6 & 58 & $0.018 \pm 0.04$ & 0.62 \\
\hline MAF $50^{\circ}$ & 4 & 46 & $-0 \cdot 014 \pm 0 \cdot 04$ & 0.68 \\
\hline HEL $10^{a}$ & 19 & 35 & $0.014 \pm 0.06$ & 0.80 \\
\hline \multicolumn{5}{|l|}{ Sire 839803} \\
\hline RM002 & 23 & 100 & $-0.048 \pm 0.018$ & $0.006^{* *}$ \\
\hline $\mathrm{CYP} 21^{\mathrm{a}}$ & 23 & 136 & $-0.025 \pm 0.011$ & $0.05^{\star}$ \\
\hline $\mathrm{RM} 185^{\circ}$ & 23 & 63 & $-0.046 \pm 0.03$ & 0.13 \\
\hline $\operatorname{CSSM} 24^{\circ}$ & 23 & 101 & $0.032 \pm 0.26$ & $0 \cdot 26$ \\
\hline TGLA53 & 16 & 61 & $-0.022 \pm 0.032$ & 0.65 \\
\hline $\mathrm{BM} 6108^{\mathrm{a}}$ & 12 & 81 & $0.037 \pm 0.028$ & 0.15 \\
\hline$I G F-1^{\mathrm{t}}$ & 5 & 63 & $0.06 \pm 0.054$ & $0 \cdot 21$ \\
\hline $\mathrm{BM} 1329^{b}$ & 6 & 111 & $0.004 \pm 0.02$ & 0.83 \\
\hline
\end{tabular}

t Denotes markers associated with ovulation rate in daughters $(P<0 \cdot 10)$.

$\neq$ Based on data generated in this study chromosome 7 and 23 marker maps are (CSSM29 - 8 CM - UWCA20 - 24 CM - RM006 - 8 cM - ILSTS001 - $16 \mathrm{cM} \mathrm{-}$ BM7160) and (RM002 - $1 \mathrm{CM}-\mathrm{CYP} 21-6 \mathrm{CM}-\mathrm{RM} 185-16 \mathrm{cM}-\mathrm{CSSM} 24)$, respectively.

$\$$ Sire allele 1 vs sire allele 2 .
In sire group 839802, markers flanking UWCA20 on chromosome 7 included CSSM29 (Moore et al. 1994), RM006 and BM7160 (C. Beattie, unpubl. obs.). Interestingly, CSSM29 was not significant, RM006 was significant and BM7160 was highly significant. Owing to the large distance (>40 cM, C. Beattie, pers. comm.) between the two highly significant loci, UWCA20 and BM7160, it could be hypothesized there were two separate ovulation rate QTL present on chromosome 7. However, the data presented here are insufficient to resolve the hypothesis of two QTL at a distance on chromosome 7 versus the alternative of a single, intermediately located QTL.

The three markers flanking CYP21 on chromosome 23 in sire group 839803 were RM002, RM185 and CSSM24. RM002 was significantly associated with ovulation rate, whilst RM185 and CSSM24 were not significant. Similarly, UWCA1 investigated in the daughter analysis was also non-significant $(-0.044 \pm 0.03 ; P=0.14)$.

\section{Discussion}

In two of three elite sire groups there was good evidence for a molecular marker linked to a QTL that accounted for a significant proportion of the genetic variation in ovulation rate. UWCA20 in particular seemed a very robust marker for ovulation rate within the 839802 family. The UWCA20-linked QTL had an effect of greater than one phenotypic standard deviation and accounted for approximately $10 \%$ of the phenotypic variation when analysed using raw ovulation rate data. The magnitude of this effect was approximately the same, regardless of whether it was measured in daughters, daughters and granddaughters, granddaughters alone, or indeed against all other dam alleles collectively. The fact that the QTL effect remained consistent in size and significance across generations provides very strong evidence that UWCA20 was linked to a true QTL for ovulation rate within the 839802 sire family.

We hypothesize that two QTLs for ovulation rate may be present on chromosome 7 , segregating within sire group 839802. The reasoning behind this is two-fold. Firstly, UWCA20 and BM7160 were separated by greater than $40 \mathrm{cM}$ and as a consequence would be considered essentially unlinked. Secondly, if only one intervening QTL was involved, the intervening markers RM006 $(P=0.04)$ and ILSTS001 $(P=$ 0.1 ) would be expected to have estimates of effect greater than those found with UWCA20 and BM7160. Unfortunately, the lack of informative granddaughters for BM7160 meant that 
161

QTL for ovulation rate in cattle there was no opportunity to independently validate the putative association with ovulation rate. Given the limited sample size in this study and the varying marker informativeness, it is conceivable that the lesser significance of the intervening markers is a sampling effect. Consequently the results are also compatible with a single QTL centrally located between UWCA20 and BM7160. Analysis of additional data will be required to draw conclusions regarding the presence of one versus two QTL on chromosome 7.

As described in Table 3, CYP21 was significantly associated with ovulation rate, and a very closely linked marker, RM002 (W. Barendse, pers. comm.), was also significant. The CYP21linked QTL had an effect of less than one half of one phenotypic standard deviation and accounted for approximately $4 \%$ of the phenotypic variation when analysed using raw ovulation rate data. Because of the relatively smaller size of this QTL and the relatively small number of animals genotyped, it is not surprising that the somewhat distant markers UWCA1, RM185 and CSSM24 were not significantly associated with ovulation rate. Unlike UWCA20, CYP21 was only significant at the $5 \%$ level when analysed in granddaughter data. A possible explanation for this may involve the scenario where linkage between the putative ovulation rate QTL and CYP21 was weakened by recombination evidence in the granddaughter generation.

In an effort to ensure that any significant associations were not merely functions of EBV, analyses employing raw ovulation rate from daughters and granddaughters were also performed. Marker associations were analysed either as described above (substituting raw ovulation rate for EBV, with paternal allele inheritance treated as a covariate) or by analysis of ovulation rate in a mixed effects model that accounted for genetic relationships and treated marker inheritance as a fixed effect. Reassuringly, results from these analyses were consistent with the results observed when using EBVs as data.

In the work described here, a total of 77 genetic markers were used in searching for linkage with ovulation rate, with each marker analysed separately. Because so many multiple comparisons were made, a number of significant associations found in the original daughter analysis may have occurred purely by chance. This problem has been recognized for decades (Niemann-Sorenson \& Robertson 1961) and numerous methods have attempted to address it (Cooper 1968; Prentice et al. 1984). In general, these methods are reliant upon increasing significance level and although this decreases incidence of type-I error, it also increases type-II error. Ultimately, the true test of an association is to test the marker in another independent sample, or to select animals on basis of marker genotype and measure them for the trait of interest. In this study, the use of granddaughters as a confirmation tool, plus genotyping flanking markers, were important safeguards in minimizing spurious associations.

\section{Acknowledgements}

The authors thank Dr Craig Beattie for kindly providing microsatellite markers prior to publication; Steve Kappes, Darell Light and Gordon Hayes, Roman L. Hruska US Meat Animal Research Center for excellent operational assistance; and Becky Huff, University of WisconsinMadison, for excellent technical assistance. This work was funded in part by grants from USDA National Research Initiatives programme (9237205-7930) and College of Agricultural and Life Sciences, University of Wisconsin-Madison (Hatch Grant No. 3352). This study was conducted under Memorandum of Understanding 58-82HW-M-47 between the Department of Meat and Animal Science, University of WisconsinMadison and the Roman L, Hruska US Meat Animal Research Center, ARS, USDA Clay Center, Nebraska.

\section{References}

Anderson G.B., Cupps P.T. \& Drost M. (1979) Induction of twins in cattle with bilateral and unilateral embryo transfer. Journal of Animal Science 49, 1037-42.

Andrews L.D., Harris Jr G.C., Stumps L., Clowser W.B. \& Yates J.D. (1988) The performance of broiler hens at two different body weights. Poultry Science 67 (Suppl. 1), 48.

Barendse W., Armitage S.M., Kossarek L.M. et al. (1994) A genetic linkage map of the bovine genome. Nature Genetics 6, 227-35.

Bellows R.A., Short R.E. \& Staigmiller R.B. (1979) Research areas in beef cattle production. In: Beltsville symposia in agriculture (ed. by H.W. Hawk), 3, pp. 3-18.

Bishop M.D., Kappes S.M., Keele J.W. et al. (1994) A genetic linkage map for cattle. Genetics 136, 619-39.

Cooper D.W. (1968) The significance level in multiple tests made simultaneously. Heredity 23, 614-7.

Darvasi A. \& Soller M. (1992) Selective genotyping for determination of linkage between a marker locus and a quantitative trait locus. Theoretical and Applied Genetics 85, 353-9.

Dentine M.R. \& Cowan C.M. (1990) An analytical model for the estimation of chromosome substitution effects in the offspring of individuals heterozygous at a segreating marker locus. Theoretical and Applied Genetics 79, 775-80. 
162

Blattman,

Kirkpatrick, Gregory
Dickerson G.E. (1978) Animal size and efficiency: basic concepts. Animal Production 27, 367-79.

Dickerson G.E., Guerra-Martinez P., Anderson G. \& Green R. (1988) Twinning and efficiency of beef production. Beef Research Progress Report No. 3, 31-3.

Echternkamp S.E., Gregory K.E., Dickerson G.E., Cundiff L.V., Koch R.M. \& Van Vleck L.D. (1990a) Twinning in cattle II. Genetic and environmental effects on ovulation rate in puberal heifers and postpartum cows and the effects of ovulation rate on embryonic survival. Journal of Animal Science 68, $1877-88$.

Gregory K.E., Echternkamp S.E., Dickerson G.E., Cundiff L.V., Koch R.M. \& Van Vleck L.D. (1990) Twinning in cattle: I. Foundation animals and genetic and environmental effects on twinning rate. Journal of Animal Science 68, 1867-76.

Groeneveld E., Kovac M. \& Wang T. (1990) PEST, a general purpose BLUP package for multivariate prediction and estimation. In: Proceedings of the 4th World Congress on Genetics Applied to Livestock Production, Edinburgh. XXIII, 488-91.

Kemp S.J., Hishida O., Wambugu J. et al. (1995) A panel of polymorphiv bovine, ovine and caprine microsatellite markers. Animal Genetics (In press).

Montgomery G.W., Crawford A.M., Penty J.M. et al. (1993) The ovine Booroola fecundity gene $\left(\mathrm{Fec}^{\mathrm{B}}\right)$ is linked to markers from a region of human chromosome 4q. Nature Genetics 4, 410-4.

Moore S.S., Byrne K., Berger K.T. et al. (1994) Characterization of 65 bovine microsatellites. Mammalain Genome 5, 84-90.

Mullenbach R., Lagoda P.J.L. \& Welter C. (1989) An efficient salt-chloroform extraction of DNA from blood and tissues. Trends in Genetics 5, 12.

Neimann-Sorensen A. \& Robertson A. (1961) The association between blood groups and several production characteristics in three Danish cattle breeds. Acta Agriculturae Scandinavia 11, 163-96.

Prentice R.L., Storb R., Brown K. \& Mason M.W. (1984) HLA and disease: relative risk regression methods and multiple testing considerations. Biometrics $\mathbf{4 0}$, 653-61.

Rutledge J.J. (1975) Twinning in cattle. Journal of Animal Science 40, 803-15.

Sun H.S., Dentine M.R., Barendse W. \& Kirkpatrick B.W. (1994) UWCA19 and UWCA20: polymorphic bovine microsatellites. Animal Genetics 25, 121. 